\title{
Melody of Functions and Graphs: Improving Senior Secondary Mathematics Students' Understanding of the Function Concept by Active Integration of Mathematics and Music
}

\author{
István Nagy ${ }^{*}$, John Malone \\ Curtin University, Australia.
}

\begin{abstract}
How to cite this paper: István Nagy, John Malone. (2020). Melody of Functions and Graphs: Improving Senior Secondary Mathematics Students' Understanding of the Function Concept by Active Integration of Mathematics and Music. The Educational Review, USA, 4(8), 157-165.

DOI: 10.26855/er.2020.08.001
\end{abstract}

Received: June 8, 2020

Accepted: July 12, 2020

Published: August 20, 2020

Corresponding author: Dr István

Nagy, Curtin University, Australia.

Email:

Istvan.Nagy@postgrad.curtin.edu.au

\begin{abstract}
This paper describes a study involving the active integration of mathematics and music applied to the process of senior secondary students' understanding of the function concept. The study has used the frame of the post-positivist paradigm, quasi-experimental research design, multiple research methods, experimentaland control-groups, pre-tests and post-tests. The study has considered nine author-developed analogies between mathematics and music as tools to improve students' understanding of the function concept. The findings suggest that this type of active integration of mathematics and music makes a statistically significant difference in students' understanding of function.
\end{abstract}

\section{Keywords}

Active Integration of Mathematics and Music, Musical analogy, Function, Translation, Dilation

\section{Introduction}

This research was carried out in an effort to actively integrate mathematics with music and to use combined intelligence channels in order to improve 16-17 years old senior secondary students' understanding of function. This study aimed to determine any positive effects of this integrated method which could be employed in the curriculum. The study was not about passive listening to music in mathematics lessons, but involved the active integration of mathematics and music in the form of analogies, as tools, in order to improve students' understanding of function concept as described the Australian Curriculum (2014).

The study has addressed the following research question: Does this type of active integration of mathematics and music make a significant difference in students' understanding of function? The importance of the question is reflected by the fact that understanding of the concept of function is crucial in mathematics. The study has targeted the six components of the function topic, as defined in the Australian Curriculum (2014):

ACMMM022: "understand the concept of function as a mapping between sets"

ACMMM023: "use function notation, domain and range, independent and dependent variables"

ACMMM024: "understand the concept of the graph of a function"

ACMMM025: "examine translations and the graphs of $y=f(x)+a$ and $y=f(x+b)$ "

ACMMM026: "examine dilations and the graphs of $\mathrm{y}=\mathrm{c} \times \mathrm{f}(\mathrm{x})$ and $\mathrm{y}=\mathrm{f}(\mathrm{k} \times \mathrm{x})$ "

ACMMM027: "recognise the distinction between functions and relations, and the vertical line test". 


\section{Background, Analysis of the Research Literature}

Mathematics and music have a very complex relationship. They are two universal languages, two ways of expressing patterns of human rational thoughts and emotional feelings. The relationships between mathematics and music have been researched in a range of different ways, and research has suggested that music can enhance students' academic outcomes in mathematics (An, Zhang, Tillman, Lesser, Siemssen, \& Tinajero, 2016; Evans, 2009; Harris, 2005; Nisbet, 1998; Rauscher, 2003; Schumacher, Altenmüller, Deutsch, \& Vitouch, 2006; Still \& Bobis, 2005; Spychiger, 2001; Vaughn, 2000). Because students possess different mixtures of skills, integrated teaching approaches can be used to empower the understanding of an abstract mathematical concept like function by using different intelligences. Dienes (1987) has developed a sequence of different structured activities, named lessons, integrating music and literature to teach both explicitand hidden mathematics. He has used games, songs, and dance to teach abstract mathematical concepts. As the creator of the Six-stage theory of learning mathematics, Dienes (2004) identified an analogy between interpreting music and teaching mathematics.

Learning mathematics is a long, complex process which can be aided, in part, by some non-mathematical approaches. One of the possible non-mathematical aids is using different skill transfer effects between music and mathematics (McKeachie, 1987). Vaughn (2000) synthesised a range of research articles on this topic, and found a general modest support for the oft claimed relationship between mathematics and music. A range of research evidence shows that kindergarten and primary students who receive music education achieve better mathematical results than their peers who do not receive music education (Harris, 2005). The relationships between mathematics and music can serve as indicators for teachers and learners of mathematics and potentially can be used to improve the mathematical learning outcome (Harris, 2005; Kelstrom, 1998; Nisbet, 1998; Spychiger, 1999a; Spychiger, 1999b).

The concept of function is a very important concept in mathematics. The process of understanding of the concept of function has been widely researched. Laverne (1971) identified five stages in understanding of the concept of function. Vinner (1983) showed that secondary students' concept image of function is different to the concept definition of function. Clement (2001) analysed students' understanding of function through function concept images and showed why students may confuse functions and relations. Evangelidou, Spyrou, Elia, and Gagatsis (2004) have outlined university students' misunderstandings of the concept of function. Brown (2009) reported on the analysis of function concepts maps.

Nisbet (1998) claims that students are able to match melodies with their visual representations, namely with line graphs and music notations, and this is positively related to both mathematical and musical ability. Nisbet stated that further research is required to find out how audio and visual representations of mathematical functions can assist mathematics students, including visually impaired students, in understanding functions in algebra, calculus and statistics. Nisbet in an email to the first author indicated his interest in this study's plan to address one aspect of this question (S. Nisbet, personal communication, 11th November 2010). This study can be considered as an extension of Nisbet's study as it has used analogies between mathematical and musical representations of function. The participants observed, saw, and heard nine analogies between different aspects of function and their corresponding musical representations. The outcomes are in perfect accordance with Nisbet's findings.

Regarding the possible positive effects of music on mathematics achievement, Kelstrom (1998) stated that these have been poorly employed in the curriculum, and Rauscher (2003, p. 4) concludes that "music may act as a catalyst for cognitive abilities in other disciplines". In their study about common misperceptions in learning mathematics and music and the interactions of these disciplines, Malone, Leong, and Lamb (2001, p. 6) state that "music provides the reality and physical experiences corresponding to mathematical abstractions". Using analogies in teaching can be beneficial in observing inter-concept similarities, understanding new concepts and in improving attitudes (Treagust, 2001). By targeting the concept of function, using analogies and observing inter-concept similarities between mathematics and music, this study fully supports Treagust’s findings.

\section{Rationale, the Framework of the Study}

The research methodology took the form of an action research study designed to observe if the first author (the practitioner) could improve his students' understanding of the function concept. An experimental and a control group were randomly assigned out of the existing two Year 11 Mathematical Methods classes at a secondary college in Adelaide in 2016. Forty-four students participated in the study. The research was ethical and fair, showing respect toward all participants, without advantaging or disadvantaging any of the participants. The internal validity of the research was assured by the high degree of equivalence of the two groups before and during the research. The two groups, each with 22 students, were highly equivalent in that there were no significant differences in mathematical ability, music studies, learning environment, and taught curriculum. The research was conducted within the post-positivist paradigm, using the scientific 
method, quasi-experimental, two-group, pre- and post-tests research design, and involved the collection of quantitative data. Three different research methods have been used: questionnaires, measurements, and statistical analysis. The independent variables include: gender, mathematics knowledge, music training, mathematics-related beliefs and attitudes, and learning environment indicators. The six dependent variables express the extent of understanding of different aspects of the topic of function as defined in the Australian Curriculum (2014).

Both groups had learned the topic of function eight months before the pre-test. The mathematics curriculum, textbook, exercises, and tests were the same for both groups. In order to answer the research question and to monitor the equivalence of the groups, a wide range of data was collected from each participant student, representing two different categories of information: (1) students' knowledge of function and (2) students' attitudes and beliefs regarding mathematics and their learning environment. The first category of data was collected by measurement, using a mathematics test constructed by the first author based on the students' mathematics book and on the objectives of the Australian Curriculum (2014).

The 10 main questions (36 sub-questions, 60 marks) of the mathematics test were from the students' textbook, Haese Mathematics (2015), used with the written permission of the publisher. The test questions have targeted the six function components weighted as follows: M022 (the concept of function) 11 marks; M023 (function notation) 9 marks; M024 (graph of a function) 10 marks; M025 (function translations) 12 marks; M026 (function dilations) 6 marks; and M027 (functions and relations) 12 marks. Data in the second category, describing different non-intellective indicators, were collected by using three questionnaires with proven validity and reliability, namely the (1) WIHIC - What Is Happening In This Class (Fraser, 1998); (2) TOMRA - Test of Mathematics-Related Attitude (Fraser, 1981; Taylor, 2004), and (3) MRBQ - Mathematics Related Beliefs Questionnaire (Op’t Eynde \& De Corte, 2003).

\section{Treatment: The Nine Relevant Analogies}

The students have interacted with the Original Sine (2014) software, experiencing sounds when changing frequency and amplitude, then the following nine analogies were presented:

Analogy 1: Mathematical Function $\approx$ Musical Melody

The students had observed that if they press one key each time on the Virtual Piano (2015) and if $t$ denotes the time and $f(t)$ the frequency of the sound at the time $t$, then the played melody can be represented by the function $y=f(t)$. This constitutes the analogy between the function and the melody. For example, the W.A. Mozart: Variations in C, K.265 (300e), the "Twinkle, twinkle, little star" - melody is represented as a time-frequency function in Figure 1.

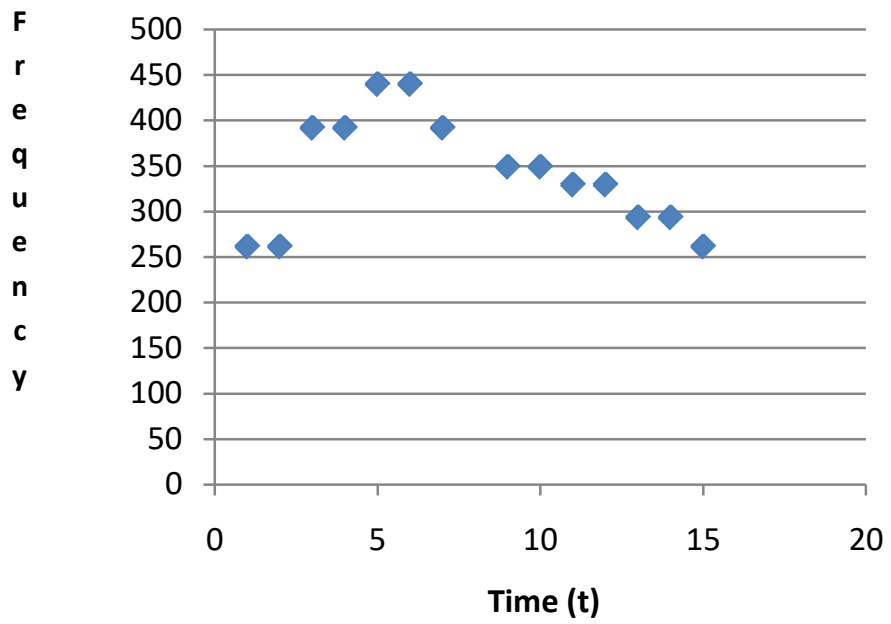

Figure 1. Mathematical function $\approx$ Musical melody.

Analogy 2: Mathematical Relation $\approx$ Musical Harmony

If two or more piano keys are pressed at the same time, then there are two or more sounds at that time. This is a musical harmony. Because multiple frequencies are allocated to a time point, the harmony can be represented by using a mathematical relation. This constitutes the analogy between the concepts of mathematical relation and musical harmony (Figure 2). 


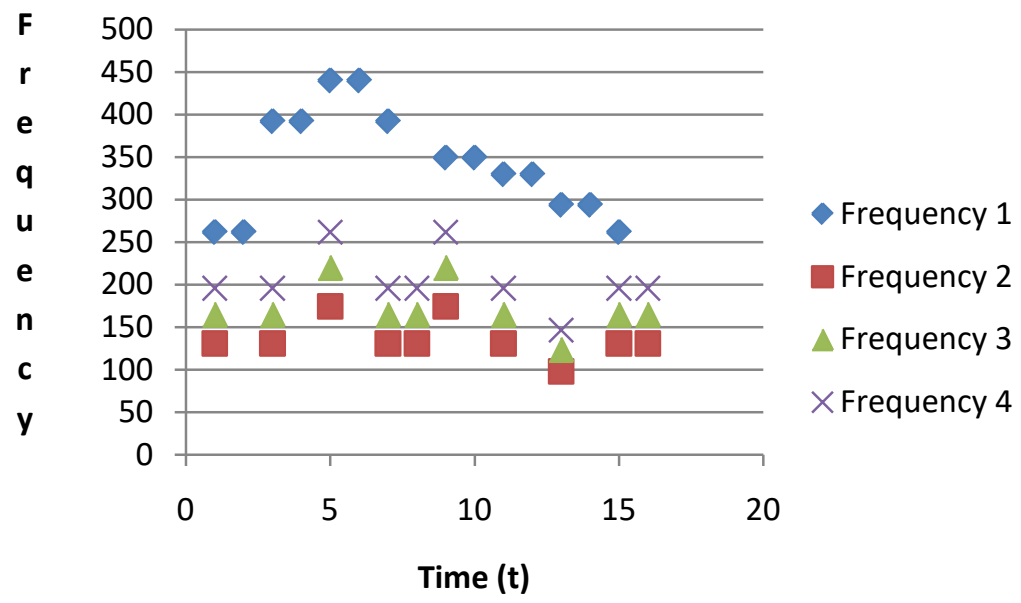

Figure 2. Mathematical relation $\approx$ Musical harmony.

Analogy 3: Vertical Line Test for Function $\approx$ Test for Two Aspects of Music

The musical analogy of the Vertical line test for function is the Test for two aspects of music (melody or harmony). If there is at least one time having more than one musical sound then that music piece is a harmony otherwise it is a melody. The students have listened to "Prelude in C-minor Op. 28 No. 20" piano piece by F. Chopin, have checked the music sheet simultaneously, and have empowered their knowledge regarding the Vertical line test for function, concluding that this music is a harmony and is represented by a relation.

Analogy 4: Graphs of Multiple Functions $\approx$ Musical Counterpoint

The students have listened to and have checked the music sheet of J. S. Bach's beautiful music, "Arioso from Cantata, $B W V 156$ ", which is a harmony, but a special one: there are two melodies sounding at the same time. There is no any other harmonization in this piece of music. This type of harmony is a musical counterpoint. The mathematical analogy of the musical counterpoint is plotting multiple graphs of different functions on the same axes.

Analogy 5: Vertical Translation of Function $\approx$ Transposition of Melody

The vertical translation of a function has the analogy of transposition of a melody. If the piano key number function $n=$ $f(t)$ is translated by a constant $a$, which means $g(t)=f(t)+a$, then the same melody is played, but $a$ halftones higher. E.g., considering the piano key difference of 7 between $C$ (key 40) and $G$ (key 47) on the piano, then $f(t)$ and $g(t)=f(t)+7$ are the piano key number functions of the melody in $C$-major and in $G$-major (Fig. 3).

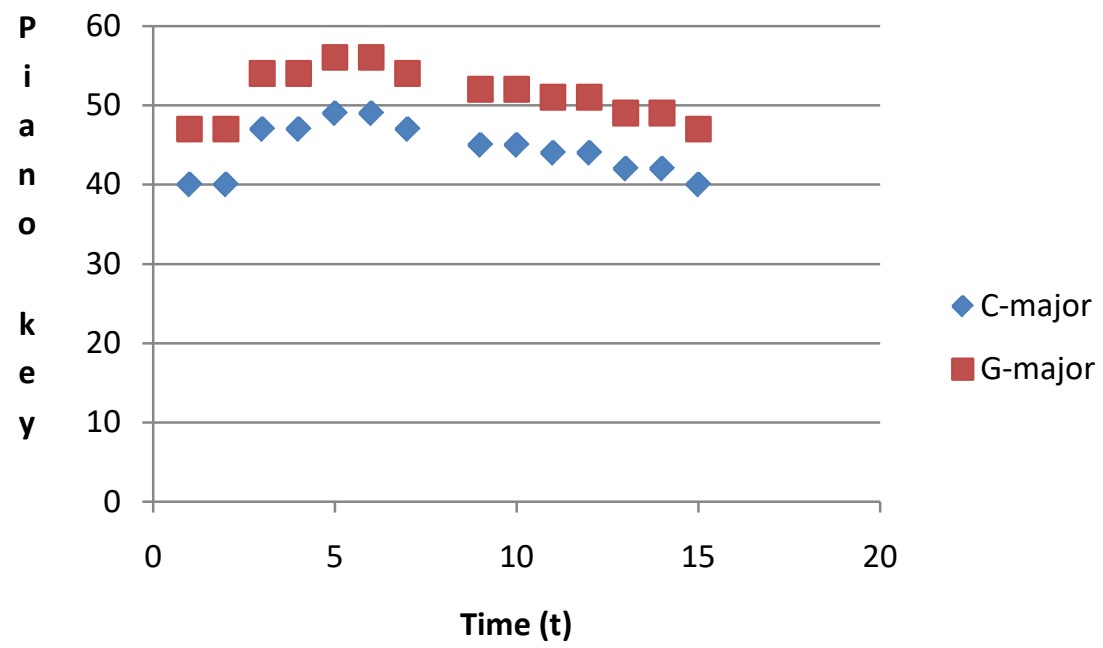

Figure 3. Vertical translation of function $\approx$ Transposition of melody. 
Analogy 6: Horizontal Translation of Function $\approx$ Repetition of Melody

The horizontal translation of a function $f$ by a constant $b, g(t)=f(t+b)$, has an analogy in music: the musical repetition of the corresponding melody.

Both the melody function $f(t)$ and its horizontal translation, the new function $(t)=f(t-20)$, representing the repetition of the melody, are displayed in Figure 4. In this case, the horizontal translation constant is $b=-20$.

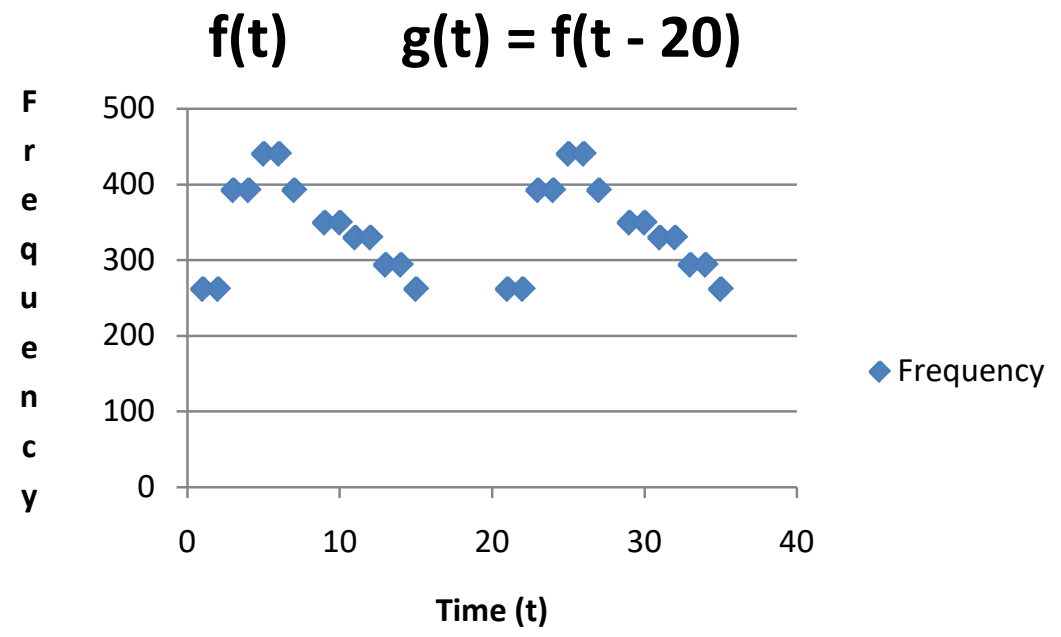

Figure 4. Horizontal translation of function $\approx$ Repetition of melody.

The vertical dilation of a function by a constant $c>0, g(x)=c \times f(x)$, has two analogies:

Analogy 7: Vertical dilation of the amplitude function $\approx$ Loudness of the music

If $y=A(t)$ is the amplitude function of a melody, then the vertical dilation $c \times A(t)$ represents the increase (if $c>1$ ) or the decrease (if $0<c<1$ ) of the loudness of the music.

Analogy 8: Vertical dilation of the frequency function $\approx$ Transposition of the music

If $y=f(t)$ is the frequency function of a melody, and the constant $c=2^{N / 12}(\mathrm{~N}=1,12)$ is an element in the geometric progression $2^{1 / 12}, 2^{2 / 12}, 2^{3 / 12}, \ldots, 2^{12 / 12}$, then the vertical dilation $g(t)=c \times f(t)$ represents a musical transposition of the melody by $\mathrm{N}$ halftones up. For example, if $f_{C}(t)$ represents the frequency function of the melody in $C$-major and $c=2^{7 / 12}$ then the vertical dilation $f_{G}(t)=2^{7 / 12} \times f_{C}(t)$, represents the melody in G-major (Figure 5).

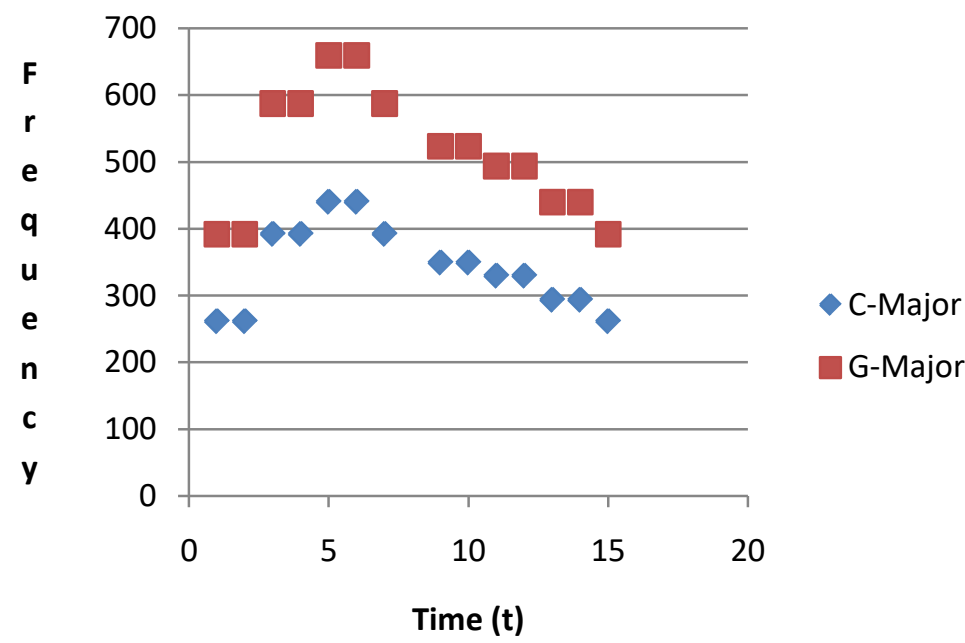

Figure 5. Vertical dilation of frequency function $\approx$ Transposition of music. 
Analogy 9: Horizontal Dilation of Function $\approx$ Change of the Tempo of Music

A horizontal dilation of a function $f(t)$ by a constant $d>0$, namely, $g(t)=f(d \times t)$ has an analogy in music: change of the tempo (speed) of music. Let $f(t)$ be the frequency function of a melody. If $0<d<1$ then $t>d \times t$ and as a result, the sound frequency $g(t)=f(d \times t)$ will occur at a later time than the sound frequency $f(t)$. In this case, the tempo (speed) of the melody represented by $g(t)$ is slower than the tempo of the melody represented by $f(t)$. E.g., the melody $f(t)$ and its horizontal dilation by $d=0.5$, the slower melody $g(t)=f(0.5 \times t)$ (Figure 6). The students have interacted with the Music Speed Changer (2012) software.

If $d>1$ then $t<d \times t$ and as a result, the sound frequency $g(t)=f(d \times t)$ will occur at an earlier time than the original sound frequency $f(t)$. In this case, the tempo (speed) of the melody represented by $g(t)$ is faster than the tempo (speed) of the melody represented by $f(t)$.

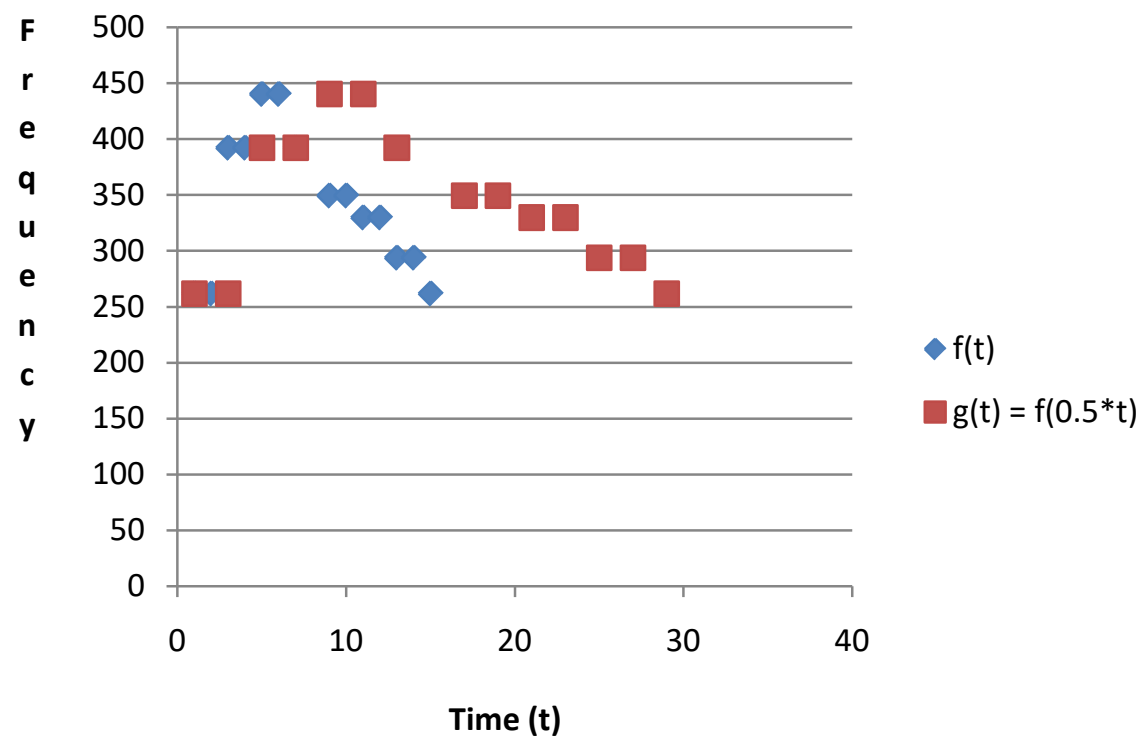

Figure 6. Horizontal dilation of frequency function $\approx$ Change of the tempo of music.

During the treatment above, developed and taught by the first author, presented in a 90 minute double-lesson, as a revision of the function topic, students' active contribution was encouraged. The students have interacted with the following software: Original Sine (2014), Virtual Piano (2015) and Music Speed Changer (2012) and have observed and enjoyed these nine musical analogies. The first author also taught the control group in a 90 minute double-lesson on the same day, reviewing the six targeted components of the function topic in a traditional way, without presenting any musical analogy. Both groups’ post-tests were administered three days after the treatment lesson.

\section{Statistical Results, Discussion of Data Findings}

The null hypothesis of the research was that this type of active integrating of mathematics and music does not make a significant difference in students' understanding of the concept of function. In order to avoid committing any type of error in retaining or rejecting the null hypothesis, the statistical significance level of the study has been set a priori at $\alpha=5 \%$, hence the confidence interval can be stated with a 95\% confidence level.

The mathematics tests have been scored by the first author. In order to avoid research bias, a strict marking scheme was set a priori. The pre-test and post-test achievement percentages have been calculated for both groups and every variable. The post-test - pre-test differences of achievement percentages per group per variable and the General indicator summarising the increase or decrease of the achievement percentages are figured in Table 1 below.

Table 1. Differences of achievement percentages per group per component and General

\begin{tabular}{cccccccc}
\hline Group $\mid$ Variable & M022 & M023 & M024 & M025 & M026 & M027 & General \\
\hline Experimental & $14.88 \%$ & $0.51 \%$ & $-5.45 \%$ & $21.59 \%$ & $8.33 \%$ & $0.00 \%$ & $7.05 \%$ \\
Control & $4.96 \%$ & $9.60 \%$ & $-9.55 \%$ & $12.50 \%$ & $3.03 \%$ & $0.00 \%$ & $3.56 \%$ \\
\hline
\end{tabular}


The indicator "General" is a derived measure, based on the total of 60 marks of the mathematics test, showing the general understanding of function by considering the weightings of the six mathematical variables. The indicator "General" is calculated as follows: General $=(11 \times M 022+9 \times M 023+10 \times M 024+12 \times M 025+6 \times M 026+12 \times M 027) / 60$.

It can be observed that the experimental group compared to the control group has achieved better results (bigger increase or smaller decrease) in four out of six components (M022, M024, M025, M026), the same result on one component (M027), and weaker result (smaller increase) on one component only (M023). Considering the general increase of 7.05\% of the experimental group compared to the $3.56 \%$ increase of the control group can be observed that the general increase of the experimental group was nearly the double of the general increase of the control group.

Three statistical analysis tests were performed: GLM (General Linear Model), MANOVA (Multivariate Analysis of Variance) and the t-test for independent two samples, using the IBM SPSS (Statistical Package for the Social Sciences) software package.

The performed GLM and MANOVA tests, which offer multivariate comparisons of two groups, indicate that there were no significant group (experimental, control), gender (female, male) and music study (yes, no) differences between the experimental and control groups ( $p>.05$ on all pairs of these independent variables). Box's Test of Equality of Covariance Matrices, performed by the GLM process, also indicates that the correlations between the dependent variables, and the standard deviations of the two groups are similar, as Box's $M=13.06, F(9,3781.94)=1.29, p=.235$. Levene's Test of Equality of Error Variances shows for the mathematics pre-tests of the two groups $F(3,40)=0.785, p=.510$; and for the mathematics post-tests $F(3,40)=1.291, p=.291$, meaning that there are no significant differences between the two groups error variances for both mathematics pre-test and post-test. The multivariate test results also show that regarding the independent variables the difference between the experimental and control groups is not significant as we have for the group variable: Wilks' Lambda $=.001, F(36,1)=36.67, p=.130$, for the gender variable: Pillai's Trace $=.982, F(36,1)=1.52, p=.578$, and for music study variable: Hotelling's Trace $=6906.43, F(36,1)=191.85, p$ $=.057$.

The t-test for independent two samples SPSS statistical analysis test was performed in order to enable making correct and valid statistical statements regarding the achievement differences between the mathematics pre-tests and post-tests of both groups.

There is statistical evidence that the increase of the mathematics achievement of the experimental group is statistically significant $(t=-2.788, p=.011)$ at $\alpha=0.05$ significance level as described in the table of the experimental group's mathematics paired samples test, Table 2 below.

Table 2. Experimental Group's Mathematics Paired Samples Test

\begin{tabular}{ccccccccc}
\hline $\begin{array}{c}\text { Exp. Group } \\
\text { Mathematics }\end{array}$ & Mean & Std. Deviation & $\begin{array}{c}\text { Std. Error } \\
\text { Mean }\end{array}$ & $\begin{array}{c}\text { 95\% C. I. } \\
\text { Lower }\end{array}$ & $\begin{array}{c}\text { 95\% C. I. } \\
\text { Upper }\end{array}$ & t & df & $\begin{array}{c}\text { Sig. } \\
\text { (2-tailed) }\end{array}$ \\
\hline Pre - Post & -4.23 & 7.11 & 1.52 & -7.38 & -1.07 & $\mathrm{t}=-2.788$ & 21 & $p=.011$ \\
\hline
\end{tabular}

Having the p-value $p=.011$, and the calculated effect size indexes of Cohen's $d=0.46$, Glass' delta $=0.48$, and Hedges' $g=0.46$, we can state that the treatment's effect was a statistically significant, medium effect size improvement of experimental group's understanding of the concept of function.

There is statistical evidence that the increase of the achievement of the control group is statistically not significant $(t$ $=-1.347, p=0.192)$ at $\alpha=0.05$ significance level (Table 3).

Table 3. Control Group's Mathematics Paired Samples Test

\begin{tabular}{ccccccccc}
\hline $\begin{array}{c}\text { Control Group } \\
\text { Mathematics }\end{array}$ & Mean & Std. Deviation & Std. Error Mean & $\begin{array}{c}\text { 95\% C. I. } \\
\text { Lower }\end{array}$ & 95\% C. I. Upper & t & $\begin{array}{c}\text { df } \\
\begin{array}{c}\text { Sig. } \\
\text { (2-tailed) }\end{array}\end{array}$ \\
\hline Pre-Post & -2.14 & 7.44 & 1.59 & -5.44 & 1.16 & $t=-1.347$ & 21 & $p=.192$ \\
\hline
\end{tabular}

The obtained p-value $\mathrm{p}=0.192$ and the calculated effect size indices Cohen's $d=0.21$, Glass' delta $=0.25$, and Hedges' $g=0.21$ indicate that the teaching practice using the traditional way of reviewing functions had a statistically not significant small effect size improvement of control group's understanding of function.

As a result, the performed statistical analysis tests indicate that the increase of the achievement of the control group is statistically not significant $(p=0.192)$ and the increase of the achievement of the experimental group is statistically significant $(p=0.011)$. This result is attributed to the treatment intervention, which means that the null hypothesis can be rejected, the answer to the research question is affirmative: Yes, this type of active integration of mathematics and music makes a significant difference in students' understanding of function. 


\section{Summary, Conclusions}

The paper presents musical analogies of different aspects of function, teaching secondary mathematics students to pass from traditional algebraic, graphical, and tabular representations of functions to musical representation. Students' existing mathematical knowledge is not contradicted or confused but, on the contrary, it is empowered and expanded through their general human musical intelligence. The study presents a unique method of teaching mathematical functions through musical analogies and offers an interesting perspective on multimodal approach of teaching and learning mathematics. The paper has potential significance for mathematics teachers, researchers, and learners, who (regardless of their music education background) can apply this type of active integration of mathematics and music successfully.

The findings of this study support the results of other researches (An et al., 2016; Evans, 2009; Guhn, Emerson, \& Gouzouasis, 2019; Harris, 2005; Kelstrom, 1998; Nisbet, 1998; Rauscher, 2003; Schumacher et al., 2006; Still \& Bobis, 2005; Spychiger, 1999a; Spychiger, 1999b; Spychiger, 2001; Vaughn, 2000) stating that music can enhance students' outcomes in mathematics. The research created new knowledge regarding the practice of improving students' understanding of function. Historically, studies integrating secondary mathematics with music are rare, as "efforts to integrate mathematics with music are rare” (Kleiman, 1991, p. 1). Hamilton, Doai, Milne, Saisanas, Calilhanna, Hilton, Goldwater, and Cohn (2018, p. 1) state that "there are very few studies which have rigorously explored the efficacy and best practice in pairing mathematics with music". The present study has specifically targeted and rigorously explored the efficacy and best practice of the improvement of secondary students' understanding of different aspects of the mathematical concept of function through the active integration of mathematics and music, a topic on which there has been a paucity of research.

The main implication of the study is that after further affirmative research results with larger samples, this type of integrated approach to improve the understanding of the mathematical concept of function may be considered for incorporation into the Mathematics curriculum of the future.

\section{References}

An, S. A., Zhang, M., Tillman, D. A., Lesser, L. M., Siemssen, A., \& Tinajero, J. V. (2016). Learning to Teach Music-themed Mathematics: An Examination of Preservice Teachers’ Beliefs about Developing and Implementing Interdisciplinary Mathematics Pedagogy. Mathematics Teacher Education and Development, 18(1), $20-36$. https://mted.merga.net.au/index.php/mted/article/view/273/255.

Australian Curriculum, v6.0. (2014). Senior secondary curriculum, Mathematical methods, Curriculum content, Unit 1, Functions and graphs. ACARA, Canberra. Retrieved from http://www.australiancurriculum.edu.au/SeniorSecondary/ mathematics/mathematical-methods/Curriculum/SeniorSecondary.

Brown, J. P. (2009). Concept maps: implications for the teaching of function for secondary school students. In R. Hunter, B. Bicknell, \& T. Burgess (Eds.), Crossing divides: Proceedings of the 32nd annual conference of the Mathematics Education Research Group of Australasia (pp. 65-72). Palmerston North, NZ: MERGA. http://www.merga.net.au/documents/BrownJ_RP09.pdf.

Clement, L. L. (2001). What do students really know about functions? Mathematics Teacher, 94(9), 745-748. http://math.buffalostate.edu/ wilsondc/med\%20308/clement_functions.pdf.

Dienes, Z. P. (1987). Lessons involving music, language and mathematics. Journal of Mathematical Behaviour, 6(2), $171-181$.

Dienes, Z. P. (2004). Mathematics as an art form. Retrieved from http://www.zoltandienes.com/wp-content/ uploads/2010/05/Mathematics_as_an_art_form.pdf.

Evangelidou, A., Spyrou, P., Elia, I., \& Gagatsis, A. (2004). University students’ concepts of function. In M. Johnsen Hoines and A. BeritFuglestad (Eds.), Proceedings of the 28th Conference of the International Group for the Psychology of Mathematics Education (pp. 351-358). Bergen, Norway: Bergen University College. http://www.emis.de/proceedings/ PME28/RR/RR099_Evangelidou.pdf.

Evans, J. K. (2009). How does integrating music and movement in a kindergarten classroom effect student achievement in math? Wayne State College, Wayne Nebraska. http://gothenburg.k12.ne.us/StaffInfoPg/Papers/J_Evans.pdf.

Fraser, B. J. (1981). TOSRA: Test of science-related attitudes. The Australian Council for Educational Research, Hawthorn, Victoria.

Fraser, B. J. (1998). Classroom environment instruments: development, validity and applications. Learning Environment Research, 1(1), 7-33. doi: 10.1023/A:1009932514731.

Guhn, M., Emerson, S. D., \& Gouzouasis, P. (2019). A Population-Level Analysis of Associations Between School Music Participation and Academic Achievement. Journal of Educational Psychology, 112(2), 308-328. http://dx.doi.org/10.1037/edu0000376.

Haese Mathematics. (2015). Mathematics for Australia_-11 Mathematical Methods_First edition. Adelaide, SA, Australia: Haese \& Harris Publications. 
Hamilton, T. J., Doai, J., Milne, A., Saisanas, V., Calilhanna, A., Hilton, C., Goldwater, M., \& Cohn, R. (2018). Teaching mathematics with music: A pilot study. doi: 10.1109/TALE.2018.8615262.

Harris, M. A. (2005). Montessori Mozart Programme. Montessori International Journal, 75(17). http://ebookbrowsee.net/montessori -mozart-programme-pdf-d325833304.

Kelstrom, J. M. (1998). The untapped power of music: Its role in the curriculum and its effect on academic achievement. NASSP Bulletin, 82(34). doi: 10.1177/019263659808259707.

Kleiman, G. M. (1991). Mathematics across the curriculum. Educational Leadership, 49(2), 48-51. http://kennytucker.cmswiki.wikispaces.net/file/view/math+across+content+article.pdf/360762558/math\%20across\%20content \%20article.pdf.

Laverne, T. H. (1971). The concept of function. State University of New York: New York City, NY. Retrieved from http://files.eric.ed.gov/fulltext/ED049926.pdf.

Malone, J., Leong, S., \& Lamb, M. (2001). Misperceptions in Mathematics and Music: An Intra- and Interdisciplinary Investigation Employing Applied Metacognition via Computer-Aided Learning. MERGA. https:/www.merga.net.au/documents/ RR_MaloneEtAl.pdf.

McKeachie, W. J. (1987). Cognitive skills and their transfer: discussion. University of Michigan, Michigan, U.S.A. http://deepblue.lib.umich.edu/bitstream/handle/2027.42/26983/0000550.pdf?sequence=1.

Music Speed Changer [computer software]. (2012). Harald Meyer Mobile Software. Retrieved from http://tequnique.com/msc.

Nisbet, S. (1998). Listen to the graph: Children's matching of melodies with their visual representations. (Unpublished Ph.D. thesis). Griffith University: Brisbane, Australia.

Op't Eynde, P., \& De Corte, E. (2003). Student's mathematics-related belief systems: Design and analysis of a questionnaire (MRBQ). Paper presented at the Annual Meeting of the American Educational Research Association, Chicago, April 21-25, 2003.

Original Sine [computer software]. (2014). The University of Adelaide, Adelaide, Australia.

Rauscher, F. H. (2003). Can music instruction affect children's cognitive development? ERIC Clearinghouse on Early Education and Parenting, ERIC Identifier: ED480540.

Schumacher, R., Altenmüller, E., Deutsch, W., \& Vitouch, O. (2006). Macht Mozart schlau? Die FörderungkognitiverKompetenzendurchMusik. [Does Mozart make clever? Advancement of cognitive competencies through music].Bildungsforschung Band, 18(1), 113-130. Berlin, BundesministeriumfürBildung und Forschung. http://www.bmbf.de/pub/macht_mozart_schlau.pdf.

Spychiger, M. (1999a). Can music in school give stimulus to other school subjects? Music Forum, 5(6), 19-22. https://www.scribd.com/document/31244333/Can-Music-in-School-Give-Stimulus-to-Other-School-Subjects.

Spychiger, M. (1999b). MachtMusikwirklichklug? [Does music make really smart?] SchweizerMusikzeitung, 2(6), 5-9.

Spychiger, M. (2001). Music education is important - Why? Bulletin of the International Kodály Society, 26(1), 32-43. http://portal.unesco.org/culture/en/files/29054/11295455821Maria_B._Spychiger.htm/Maria\%2BB.\%2BSpychiger.htm.

Still, K., \& Bobis, J. (2005). The integration of mathematics and music in the primary school classroom. Sydney: University of Sydney. http://www.merga.net.au/documents/RP822005.pdf.

Taylor, B. A. (2004). The influence of classroom environment on high school students' mathematics anxiety and attitudes. Perth: Curtin University of Technology. Retrieved from http://espace.library.curtin.edu.au:80/R?func=dbin-jump -full\&local_base=gen01-era02\&object_id=15708.

Treagust, D. F. (2001). Using analogies in science teaching to engender students' interest, motivation and understanding. In Clements, M. A., Tairub, H. H., \& Yoong, W. K. (Eds.), Energising Science, Mathematics and Technical Education for All (pp. 10-26). University Brunei Darussalam. Retrieved from http://edocs.library.curtin.edu.au/eres_display.cgi?url=dc60206572. pdf\&copyright $=1$.

Vaughn, K. (2000). Music and mathematics: Modest support for the oft-claimed relationship. The Journal of Aesthetic Education, 34(3/4), 149-166. http://www.jstor.org/discover/10.2307/3333641 ?uid=3737536\&uid=2129\&uid=2\&uid=70\&uid=4\&sid= 21104141630093.

Vinner, S. (1983). Concept definition, concept image and the notion of function. International Journal for Mathematical Education in Science and Technology, 14(3), 293-305. http://www.researchgate.net/publication/245760146_Concept_ definition_concept_image_and_the_notion_of_function.

Virtual Piano [computer software]. (2015). Crystal Magic Studio Ltd. http://virtual piano.net. 